\title{
Receptores muscarínicos na doença pulmonar obstrutiva crônica: o que é importante saber da biologia à prática clínica?
}

\author{
Muscarinic receptors and chronic obstructive pulmonary disease: \\ from biology to clinical practice
}

\author{
Letícia Ubaldo Rodrigues ${ }^{1}$, Caio Teixeira Soares ${ }^{1}$, Daniel Brandão Venuto ${ }^{1}$, \\ Renan Guimarães Santana ${ }^{1}$, Analúcia Rampazzo Xavier ${ }^{2}$, \\ Cyro Teixeira da Silva Junior ${ }^{3}$, Elizabeth Giestal de Araujo ${ }^{4}$
}

\begin{abstract}
Rodrigues LU, Soares CT, Venuto DB, Santana RG, Xavier AR, Silva Junior CT, Araujo EG. Receptores muscarínicos na doença pulmonar obstrutiva crônica: o que é importante saber da Biologia à prática clínica? / Muscarinic receptors and chronic obstructive pulmonary disease: From Biology to clinical practice. Rev Med (São Paulo). 2016 jul.-set.;95(3):128-32.

RESUMO: A doença pulmonar obstrutiva crônica (DPOC) caracteriza-se por persistente e geralmente progressiva limitação do fluxo de ar associada com uma resposta inflamatória crônica nas vias aéreas e pulmões em resposta a partículas ou gases nocivos. A prescrição de medicamentos como os antimuscarínicos é um item importante para a reabilitação pulmonar em pacientes com DPOC porque melhoram os sintomas, particularmente a dispneia e a capacidade de fazer as atividades diárias. Há evidências de alguns estudos de que também reduzam a tendência a exacerbações. Não há evidências de que broncodilatadores reduzam complicações sistêmicas, comorbidades ou tenham influência sobre a mortalidade.

ABSTRACT: The chronic obstructive pulmonary disease (COPD) is characterized by persistent and often progressive airflow limitation associated with a chronic severe inflammatory response in the airways and lungs in response to noxious particles or gases. The prescription of drugs such a muscarinic antagonist is an important step for pulmonary rehabilitation in patients with COPD because they improve symptoms, particularly dyspnea and the ability to do daily activities. There is evidence of some studies also tend to reduce exacerbations. There is no evidence that bronchodilators reduce systemic complications, comorbidities or have influence on mortality.
\end{abstract}

Descritores: Doença pulmonar obstrutiva crônica; Receptores muscarínicos; Biologia.
Keywords: Pulmonary disease, chronic obstructive; Receptors, muscarinic; Biology.

1. Internos da Disciplina de Pneumologia do Departamento de Medicina Clínica da Faculdade de Medicina da Universidade Federal Fluminense (UFF).E-mails: leticiaubaldo19@hotmail.com, ct_soaresar@yahoo.com.br_danielvenuto@id.uff.br, renangsantana@ yahoo.com.br.

2. Professora Associada do Departamento de Patologia da Faculdade de Medicina da UFF. Doutora em Bioquímica pela Universidade de São Paulo. E-mail: analuciaxavier@id.uff.br.

3. Professor Associado do Departamento de Medicina Clínica da Faculdade de Medicina da UFF. Doutor em Pneumologia e Neuroimunologia pela UFF. E-mail: ctsilvajunior@predialnet.com.br.

4. Professora Titular do Departamento de Neurobiologia do Instituto de Biologia da UFF. Doutora em Biofísica pela UFRJ. E-mail: egiestal@vm.uff.br.

Autor para correspondência: Cyro Teixeira da Silva Junior. Rua da Conceição, 13/210. Niterói, Estado do Rio de Janeiro, Brasil. CEP: 24020080. E-mail: ctsilvajunior@predialnet.com.br. 


\section{INTRODUÇÃO}

\begin{abstract}
A doença pulmonar obstrutiva crônica (DPOC) caracteriza-se por limitação do fluxo de ar, geralmente, progressiva, revela-se associada a uma resposta inflamatória crônica nas vias aéreas e pulmões em resposta às partículas ou gases nocivos ${ }^{1}$. Este trabalho objetiva atualizar na literatura a importância dos receptores muscarínicos na DPOC. Como objetivo secundário, esta comunicação tem por finalidade lembrar o médico não especialista da importância desses receptores para o tratamento da doença.
\end{abstract}

\section{Prevalência}

Segundo o Projeto PLATINO a prevalência de DPOC na cidade de São Paulo foi de 15,8\% em $2006^{2}$.

\section{Fatores de risco}

O tabagismo é o fator de risco principal para $\mathrm{DPOC}^{2,3}$. A exposição à fumaça de lenha não foi significativa na cidade de São Pauloº ${ }^{2}$ A DPOC produz consequências sistêmicas, como por exemplo, a desnutrição ${ }^{1,4}$.

\section{Diagnóstico}

O diagnóstico da DPOC faz-se necessário em qualquer indivíduo com dispneia durante os esforços e com tosse e expectoração e exposição aos fatores de risco. A prova de função pulmonar mais simples e para triagem dos pacientes é a espirometria. Um resultado de espirometria com uma razão $\mathrm{VEF} 1,0 / \mathrm{CVF}<0,70$, após prova broncodilatadora confirma a presença de obstrução de grandes vias aéreas ${ }^{1}$. No diagnóstico de pacientes com DPOC a possibilidade de sobreposição de asma e DPOC (ACOS) deve ser considerada ${ }^{5}$.

\section{Patogênese}

O estresse oxidativo, a inflamação, o desequilíbrio do sistema protease-antiprotease e a apoptose são os principais mecanismos patogênicos encontrados na DPOC e, talvez, explique os diversos fenótipos dos pacientes ${ }^{6-8}$.

\section{Fisiopatologia}

A extensão da inflamação, da fibrose e do exsudato luminal nas pequenas vias aéreas estão correlacionados com a redução do VEF 1,0 e da razão VEF 1,0/CVF em pacientes com DPOC. A obstrução das vias aéreas progressivamente aprisiona o ar durante a expiração, resultando em hiperinsuflação. Acredita-se que a hiperinsuflação se desenvolve precocemente na doença e é o primeiro mecanismo para a dispneia aos esforços. As anormalidades das trocas de gases resultam em hipoxemia e hipercapnia consequência de mecanismos diversos dentro da doença? ${ }^{7}$.

\section{Conceito de receptores biológicos}

Receptores biológicos podem ser conceituados como proteínas intrínsecas inseridas na estrutura das biomembranas. Os bioreceptores reconhecem de maneira específica grande variedade de moléculas (ligantes) para desencadear uma resposta fisiológica ${ }^{9}$. São possuidores de regiões ou sítios (domínios) extracelular, transmembrana e um domínio intracelular (citoplasmático). O domínio citoplasmático geralmente executa uma função sinalizadora para o interior da célula liberando substâncias (segundo mensageiros) que vão traduzir a ordem dada pelo ligante ou primeiro mensageiro? .

A literatura médica descreve várias categorias de receptores biológicos (Figura 1). No receptor do tipo metabotrópico, o ligante abre um canal iônico indiretamente e usa a presença de um segundo mensageiro para modificar a resposta celular de uma maneira mais demorada. $\mathrm{O}$ segundo mensageiro denominado proteína $\mathrm{G}$ é uma molécula complexa que funciona como um transdutor de sinais (Figura 2). Receptores muscarínicos existem em muitos tipos de células e participam da sinalização celular ativados pelo ligante acetilcolina. No pulmão humano, os receptores muscarínicos estão predominantemente expressos nas células musculares lisas, células epiteliais e fibroblastos 9 .

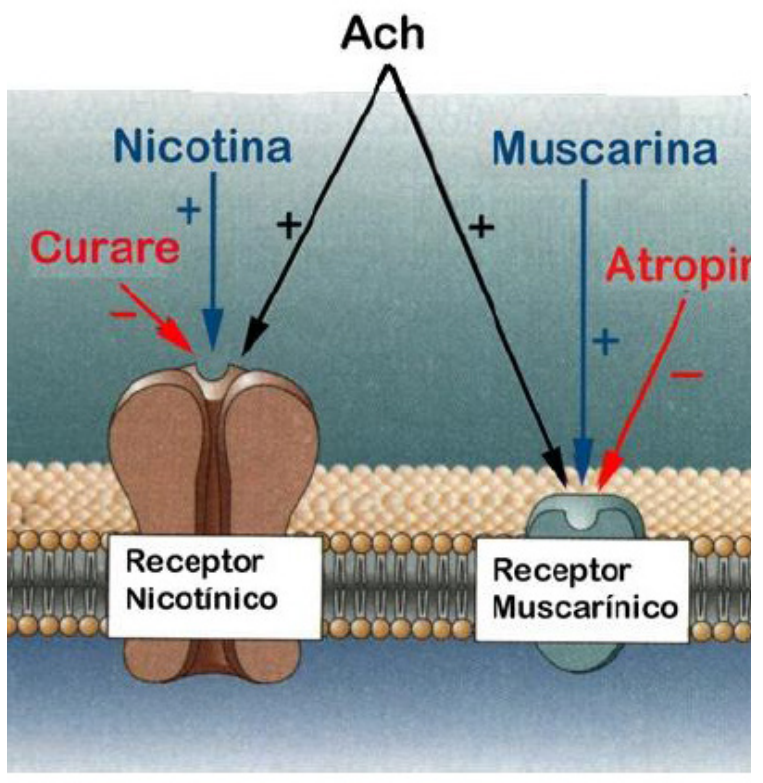

Figura 1. Ilustração dos receptores colinérgicos nicotínicos e muscarínicos com seus agonistas $(+)$ e antagonistas $(-)^{9,10}$. As setas azuis representam os agonistas e as vermelhas os antagonistas para cada sub-família de receptores ${ }^{9,10}$ 

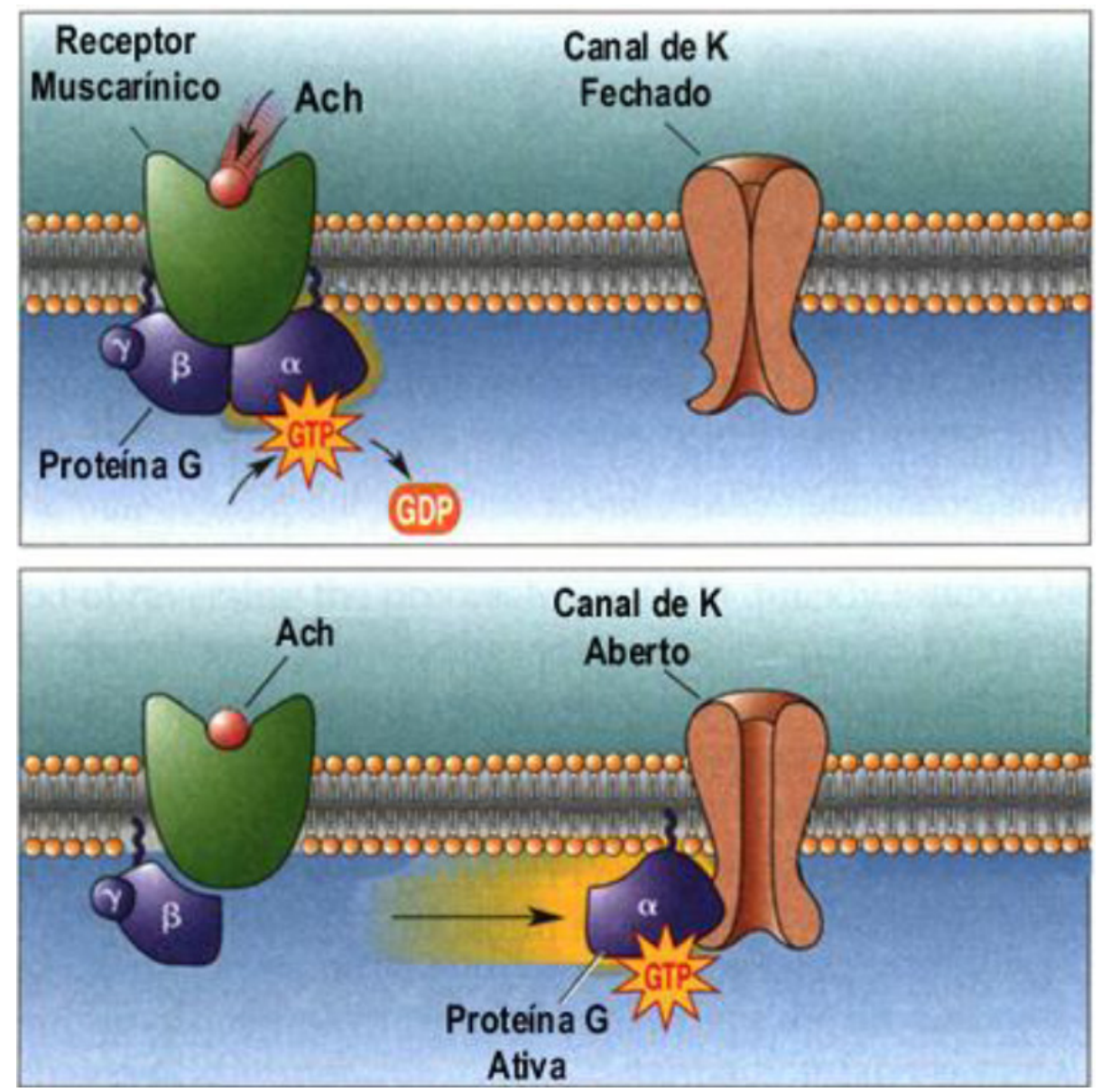

Figura 2. Ilustração dos mecanismos de ação dos receptores colinérgicos muscarínicos. Ao contrário do que acontece nos receptores ionotrópicos, os neurotransmissores agem nos receptores metabotrópicos regulando canais iônicos indiretamente (molécula efetora) através da ativação da proteína G. No exemplo, o receptor muscarínico regula a abertura do canal de potássio através da subunidade alfa da proteína $G^{9,10}$

\section{Subtipos de receptores colinérgicos muscarínicos no pulmão e DPOC}

Atualmente fármacos antimuscarínicos são utilizados para o tratamento da DPOC. São substâncias utilizadas principalmente como broncodilatadores, mas também estão associados à ação anti-inflamatória, antiproliferativa e efeitos anti-remodelamento. Os receptores muscarínicos (RCMs) de acetilcolina são do tipo metabotrópicos e pertencem à superfamilia de receptores acoplados à proteina $\mathrm{G}$. Existem cinco subtipos de receptores muscarínicos, denominados de M1 a M5 ${ }^{10}$. Em células epiteliais brônquicas humanas, demonstrou-se vários inibidores dos RCMs. O tiotrópio (antagonista de M1, M2 e M3) é o mais conhecido e divulgado ${ }^{11}$.

No pulmão humano, a concentração de inervação colinérgica parassimpática é maior nas vias aéreas proximais e diminui perifericamente. O papel predominante da acetilcolina liberada pelo sistema parassimpático é o controle da resistência das vias aéreas e da liberação de muco de glândulas submucosas e de células caliciformes ${ }^{11}$.

A estimulação de receptores M1 no pulmão humano provoca broncoconstrição. A presença de receptores M2 foi relatada no brônquio e em outros órgãos. O receptor M3 é o principal subtipo de RCM que sinaliza a contração dos brônquios e do músculo liso da traqueia, ainda que seja expressado nesses tecidos em níveis mais baixos em relação ao $\mathrm{M} 2{ }^{12}$. O receptor M3 é expresso pelas células do músculo liso das vias aéreas, por fibroblastos brônquicos humanos e por células epiteliais brônquicas, bem como no pulmão periférico humano. $\mathrm{O}$ receptor ocorre predominantemente no brônquio e a sua concentração diminui a partir do brônquio subsegmentar para segmentar e está ausente no parênquima pulmonar. A estimulação de receptores M3 no pulmão humano, músculo liso das vias aéreas centrais e no brônquio humano provoca broncoconstrição e secreção de muco a partir de glândulas submucosas. No entanto, a ativação de receptores M3 das células endoteliais vasculares induz a síntese de óxido nítrico, o qual se difunde para as células musculares lisas vasculares adjacentes e provoca vasodilatação ${ }^{11,12}$. Durante a última década, vários estudos demonstraram que a biossíntese e mecanismos de abertura dos receptores muscarínicos estão expressos independentemente da inervação colinérgica ${ }^{11}$.

A fisiopatologia de doenças pulmonares obstrutivas associa-se com a estimulação do sistema parassimpático, resultando no aumento da secreção de muco e broncoconstrição a partir de glândulas submucosas 
Rodrigues LU, et al. Receptores muscarínicos na doença pulmonar obstrutiva crônica.

das vias aéreas no pulmão humano. A atividade do receptor muscarínico da acetilcolina se encontra correlacionada na fisiopatologia da asma e DPOC, segundo estudos desde o início dos anos 70. Agentes anticolinérgicos muscarínicos provaram ser eficazes no tratamento da asma e DPOC, uma vez que o tônus colinérgico vagal parece ser um componente reversível de estreitamento das vias aéreas.

\section{Exemplos de medicamentos anticolinérgicos}

Broncodilatadores são medicamentos importantes para controlar os sintomas da DPOC. Podem ser prescritos para os momentos de exacerbações ou como uma forma de profilaxia. Pertencem à essa classe terapêutica os anticolinérgicos ${ }^{1}$. Os anticolinérgicos têm sua ação principal através do bloqueio do efeito da acetilcolina nos receptores muscarínicos. Essas drogas são mal absorvidas o que limita os efeitos sistêmicos adversos observados, por exemplo, com o uso de atropina ${ }^{1,11,12}$.

\section{Antagonistas dos receptores de acetilcolina muscarínicos de ação curta}

a) Atropina. A atropina é um alcalóide natural da beladona e possui ação anticolinérgica e antiespasmódica. Atua inibindo a atividade muscarínica da acetilcolina nos sítios neuroefetores parassimpáticos pósganglionares, inclusive no músculo liso e glândulas secretoras ${ }^{9}$. Todos os receptores muscarínicos são bloqueados pela atropina ${ }^{9,10}$.

b) Brometo de oxitrópio. O seu efeito broncodilatador é semelhante ao do brometo de ipratrópio, mas é considerado como sendo duas vezes mais potente do que o brometo de ipratrópio por dose ${ }^{13}$.

c) Brometo de ipratrópio. A inalação de brometo de ipratrópio, que inibe os receptores M1, M2 e M3, foi o primeiro inibidor muscarínico utilizado para o tratamento de pacientes com doenças pulmonares obstrutivas ${ }^{13}$.

\section{Antagonistas dos receptores de acetilcolina muscarínicos de ação longa}

a) Brometo de tiotrópio. Assim como o ipratrópio, o brometo de tiotrópio também se liga aos receptores M1, M2 e M3 e tem uma maior duração de ação anticolinérgica $^{11}$. O brometo de tiotrópio tem uma taxa de dissociação consideravelmente mais lenta em relação aos receptores M1 e M3 do que ao receptor M2, havendo seletividade cinética do fármaco para os receptores M1 e M3. Portanto, o tiotrópio é mais eficaz, uma vez que melhora a dispneia, a capacidade de exercício, reduz a hiperinsuflação e as exacerbações clínicas em pacientes com DPOC ${ }^{13}$.

b) Brometo de glicopirrônio. O brometo de glicopirrônio é um composto com alta afinidade e lenta dissociação para os receptores muscarínicos M1 e M3, em relação aos receptores M2. Nos receptores M1, o glicopirrônio tem menor ação do que o tiotrópio, reduzindo assim efeitos colaterais no sistema nervoso central e glândulas exócrinas ${ }^{14}$.

\section{Novos antagonistas dos receptores de acetilcolina muscarínicos}

\section{a) Brometo de aclidinium}

Nos brônquios humano o brometo de aclidinium tem um início de ação mais rápido, porém mais curta duração do que o brometo de tiotrópio ${ }^{13,15}$.

\section{b) Brometo de umeclidinium}

O brometo umeclidinium é um novo antagonista de ação prolongada muscarínico (LAMA) para tratamento da DPOC. É um derivado da quinuclidina com atividade ao longo de múltiplos subtipos de recetores muscarínicos. Demonstra uma reversibilidade lenta no subtipo do recetor muscarínico $\mathrm{M}_{3}$ humano in vitro e uma longa duração de ação in vivo quando administrado diretamente nos pulmões em modelos pré-clínicos ${ }^{13,15}$.

\section{Efeitos colaterais dos medicamentos anticolinérgicos}

O uso extensivo dessa classe de agentes inalatórios em largas doses em cenários clínicos diversos tem se mostrado muito seguro. O principal efeito colateral é a secura de boca e alguns pacientes relatam gosto metálico ou amargo. O uso de soluções de anticolinérgicos em máscaras faciais pode precipitar glaucoma agudo, provavelmente, devido ao efeito direto da solução no olho. Há, ainda, o relato de sintomas prostáticos ${ }^{1,11,12}$.

A ação dos anticolinérgicos sobre o sistema cardiovascular foi cercada de controvérsias nos últimos anos. Inicialmente o ipratrópio e mais recentemente o tiotrópio foram implicados em aumento do risco de eventos cardíacos. A prevenção das exacerbações com tiotrópio em pacientes com DPOC apresentou um excesso de eventos isquêmicos coronários graves com o tiotrópio em comparação com o salmeterol. Os autores recomendam cautela na prescrição de anticolinérgicos inalados para pacientes com arritmias pré-existentes ou doenças cardíacas $^{16-18}$.

Concluímos que a prescrição de medicamentos como os antimuscarínicos é um item importante para a reabilitação pulmonar em pacientes com DPOC porque melhoram os sintomas, particularmente a dispneia e a capacidade de fazer as atividades diárias. Há evidências de alguns estudos de que também reduzam a tendência a exacerbações. Não há evidências de que broncodilatadores reduzam complicações sistêmicas, comorbidades ou tenham influência sobre a mortalidade. 
Agradecimentos: O autores agradecem a Professora Dra. Tania Teixeira da Silva Nunes o valioso trabalho de revisão de língua portuguesa.

Conflito de interesses: Os autores declaram que não têm conflito de interesses com qualquer organização financeira sobre o material discutido no manuscrito. Os autores declaram também que colaboraram igualmente para a realização desse artigo e não enviaram esse manuscrito para nenhum evento científico. O presente trabalho não é parte integrante de dissertação, tese ou projeto de cursos de pósgraduação. Nunca foi apresentado em evento científico. A sua realização não teve a colaboração de agência de fomento à pesquisa do Brasil ou exterior.

\section{REFERÊNCIAS}

1. Global initiative for chronic obstructive lung disease (GOLD). Global strategy for the diagnosis, management, and prevention of COPD.Updated 2015. Available from: http://goldcopd.org/ guidelines-global-strategy-for-diagnosis-management.html.

2. Menezes AMB. PLATINO. Projeto Latino-Americano de investigação em obstrução pulmonar. 2006. Available from: www.platino-alat.org.

3. Margaritopoulos GA, Vasarmidi E, Jacob J, Wells AU, Antoniou KM. Smoking and interstitial lung diseases. Eur Respir Rev. 2015;24(37):428-35. doi: 10.1183/16000617.0050-2015.

4. Silva CS, Silva Junior CT, Silva PS, Cardoso RBB, Behrsin RF, Cardoso GP. Nutritional approach in patients with chronic obstructive pulmonary disease. Pulmão RJ. 2010;19 (1-2):40-4.

5. Tho NV, Park HY, Nakano Y. Asthma-COPD overlap syndrome (ACOS): a diagnostic challenge. Respirology. 2015. doi: 10.1111/resp.12653.

6. Dhakal N, et al. Oxidative stress and nutritional status in chronic obstructive pulmonary disease. J Clin Diagn Res. 2015;9(2):1-4. doi: 10.7860/JCDR/2015/9426.5511.

7. Bagdonas E, Raudoniute J, Bruzauskaite L, Aldonyte R. Novel aspects of pathogenesis and regeneration mechanisms in COPD. Int J COPD. 2015;10:995-1013. doi: 10.2147/ COPD.S82518.

8. Silva AL, Bresciani MJ, Karnopp TE, Weber AF, Ellwanger JH, Henriques JA, Valim AR, Possuelo LG. DNA damage and cellular abnormalities in tuberculosis, lung cancer and chronic obstructive pulmonary disease. Multidiscip Respir Med. 2015. doi: 10.1186/s40248-015-0034-z.

9. Alberts B, Johnson A, Lewis J, Raff M, Roberts K, Walter P. Molecular biology of the cell. 4th ed. New York: Garland Publishing Inc.; 2002. Available from: http://www.ncbi.nlm. nih.gov/books/NBK21054.
10. Ventura ALM, Abreu PA, Freitas RCC, Sathler PC, Loureiro N, Castro HC. Colinergic system: revisiting receptors, regulation and the relationship with Alzheimer disease, schizophrenia, epilepsy and smoking. Rev Psiq. Clin. 2010;37(2):66-72. doi. org/10.1590/S0101-60832010000200007.

11. Karakiulakis G, Roth M. Muscarinic receptors and their antagonists in COPD: anti-inflammatory and antiremodeling Effects. Mediators Inflamm. 2012;2012:409580. doi:10.1155/2012/409580.

12. Kruse AC, J Hu J, Kobilka BK, Wess J. Muscarinic acetylcholine receptor X-ray structures: potential implications for drug development. Curr Opin Pharmacol. 2014;16:24-30. doi: 10.1016/j.coph.2014.02.006.

13. Restrepo RD. Use of inhaled anticholinergic agents in obstructive airway disease. Respir Care. 2007;52:833-51.

14. Buhl R, Banerji D. Profile of glycopyrronium for once-daily treatment of moderate-to-severe COPD. Int J Chron Obstruct Pulmon Dis. 2012;7:729-41. doi: 10.2147/COPD.S36001.

15. Cohen JS, Miles MC, Donohue JF, Ohar JA. Dual therapy strategies for COPD: the scientific rationale for LAMA + LABA. Int J Chron Obstruct Pulmon Dis. 2016;11:785-97. doi: 10.2147/COPD.S54513.

16. Tashkin DP, Leimer I, Metzdorf N, Decramer M. Cardiac safety of tiotropium in patients with cardiac events: a retrospective analysis of the UPLIFT ${ }^{\circledR}$ trial. Respir Res. 2015;16:65. doi 10.1186/s12931-015-0216-4.

17. Tashkin DP. The safety of anticholinergic bronchodilators for the treatment of chronic obstructive pulmonary disease. Expert Opin Drug Saf. 2015;14(11):1759-72. doi: 10.1517/14740338.2015.1093621.

18. Singh S, Loke YK, Enright P, Furberg CD. Pro-arrhythmic and pro-ischaemic effects of inhaled anticholinergic medications. Thorax. 2013;68(1):114-6. doi: 10.1136/ thoraxjnl-2011-201275. 